\title{
Gallstone ileus: correlation between computed tomography, double-balloon enteroscopy and intra-operative findings
}

\author{
Koen J. Hartemink', Suzanne M. Hepp², Indra C. Pieters-van den Bos ${ }^{3}$, Stijn J. B. van Weyenberg ${ }^{4}$ \\ ${ }^{1}$ Department of Surgery, VU University Medical Centre, Amsterdam, The Netherlands \\ 2Department of Internal Medicine, VU University Medical Centre, Amsterdam, The Netherlands \\ ${ }^{3}$ Department of Radiology, VU University Medical Centre, Amsterdam, The Netherlands \\ ${ }^{4}$ Department of Gastroenterology and Hepatology, VU University Medical Centre, Amsterdam, The Netherlands
}

Received July 16, 2010, accepted after revision September 7, 2010, published online November 19, 2010

\section{Gallenstein Ileus: Korrelation zwischen den Ergebnissen der Computer Tomographie und der Doppel-BallonEnteroskopie mit dem intra-operativem Befund}

Zusammenfassung. Der Gallenstein-Ileus ist eine seltene Ursache für eine Obstruktion des Dünndarms. Gefährdet sind vor allem ältere Patienten. Wir berichten über eine 88-jährige Patientin, die einen solchen Gallenstein-Ileus erlitt. Die Korrelation zwischen den Ergebnissen der Computer Tomographie und der Doppel-BallonEnteroskopie mit dem intra-operativem Befund wird ebenso wie mögliche therapeutische Strategien diskutiert.

Summary. Gallstone ileus is an uncommon cause of small bowel obstruction, affecting mainly elderly patients. We report a case of gallstone ileus in an 88-year old female patient. The correlation between computed tomography, double-balloon enteroscopy and intra-operative findings is discussed, as well as treatment strategies.

Key words: Small bowel obstruction, gallstone ileus, cholecystolithiasis, computed tomography, double-balloon enteroscopy.

\section{Introduction}

Gallstone ileus is a rare complication of cholelithiasis and is an uncommon cause of mechanical bowel obstruction, affecting mainly elderly patients. It is caused by impaction of a gallstone in the jejunum or ileum after being passed through a biliary-enteric fistula. The diagnosis is often de-

Correspondence: Stijn J. B. van Weyenberg, Department of Gastroenterology and Hepatology, VU University Medical Centre, De Boelelaan 1117, 1081 HV Amsterdam, The Netherlands, E-mail: sjb.vanweyenberg@vumc.nl layed since symptoms may be intermittent and nonspecific and investigations fail to identify the cause of the obstruction [1]. Treatment consists of resuscitating the patient and removal of the obstructing stone. Gallstone ileus is associated with relatively high morbidity and mortality

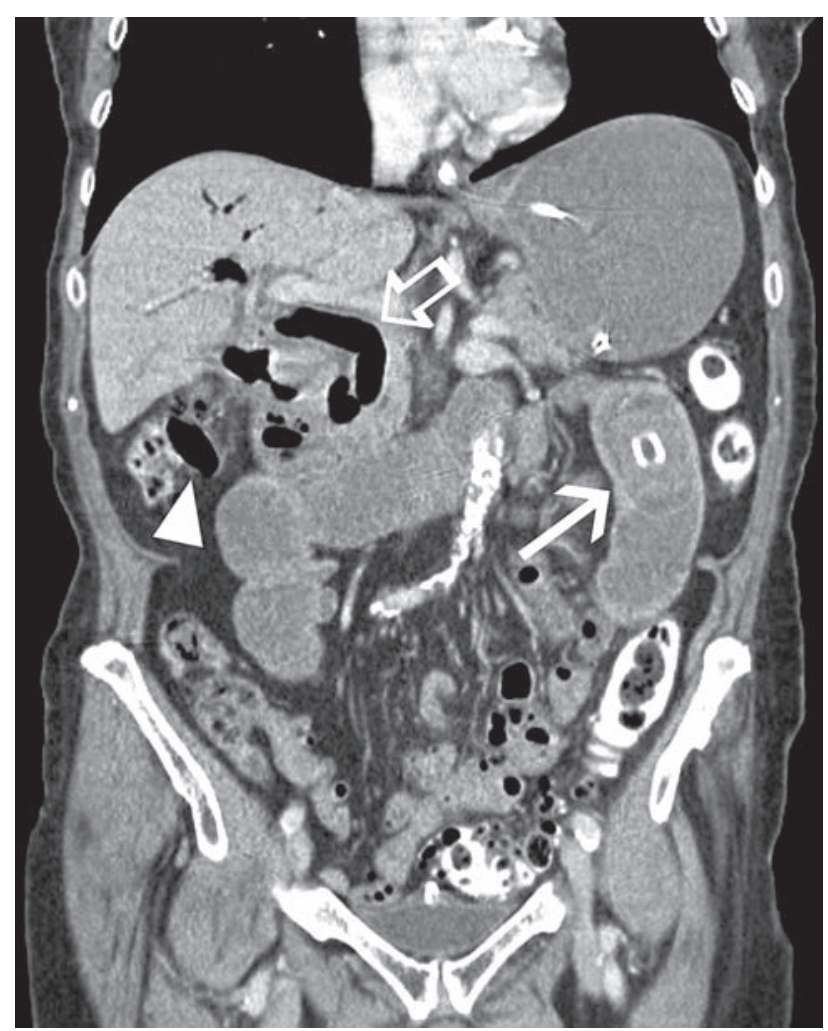

Fig. 1. CT-scan, performed after administration of intravenous, oral and rectal contrast and reconstructed in the coronal plane, shows a large gallstone (arrow) with central calcification located in the proximal jejunum. Additionally, air in the biliary system (open arrow), and in the collapsed gallbladder (arrow head) can be observed 


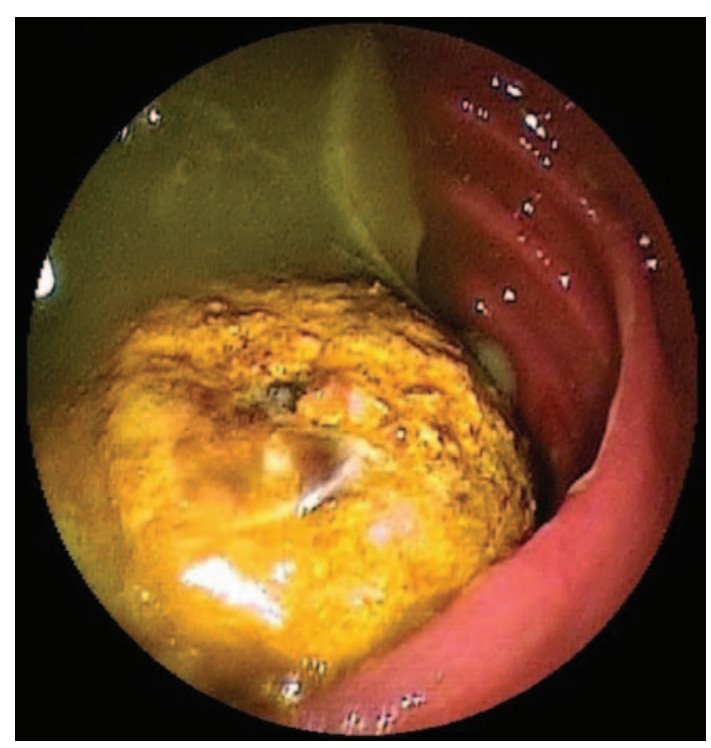

Fig. 2. Endoscopic view with double-balloon enteroscopy, showing the obstructing gallstone located in the proximal jejunum

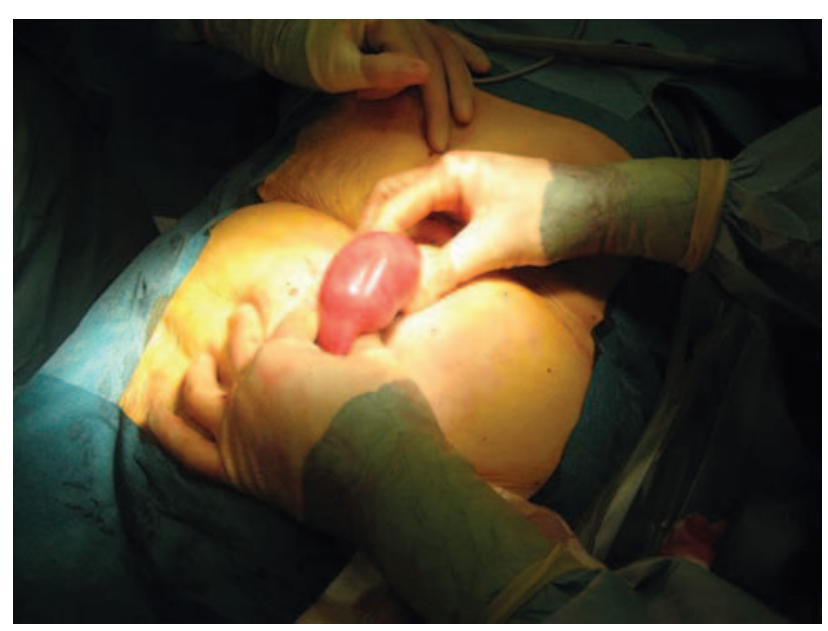

Fig. 3. Intraoperative finding of a gallstone located in the proximal jejunum

rates, since most patients present acutely, diagnosis is frequently delayed and patients have pre-existing co-morbid medical conditions [2].

\section{Case report}

An 88-year-old female patient with a medical history of ovarian cyst extraction by laparotomy was admitted to our hospital with right upper and left lower quadrant abdominal pain, vomiting and anorexia. Two years prior she was diagnosed with cholecystolithiasis, leading to cholecystitis, which was treated conservatively. No cholecystectomy was performed.

On admission, an abdominopelvic computed tomography (CT) scan showed an obstructive high ileus, based on a large, partially calcified, gallstone $(5 \times 3 \mathrm{~cm})$ which was impacted in the proximal jejunum. Also, pneumobilia, air within the collapsed gallbladder, as well as a probable fis-

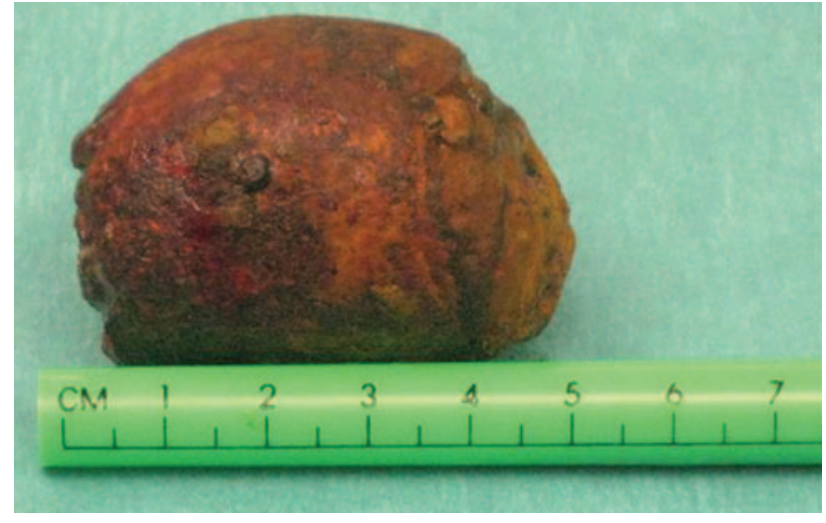

Fig. 4. The extracted gallstone, measuring 5 by $3 \mathrm{~cm}$

tula tract to the duodenum with marked surrounding edema was demonstrated (Fig. 1). Double-balloon enteroscopy was performed. Although the gallstone could be reached in the proximal jejunum, the stone was too large to be crushed with through-the-endoscope-devices such as lithotripsy baskets and polypectomy snares, or to be grasped in a retrieval net (Fig. 2). Argon plasma coagulation did not result in sufficient fragmentation either. Subsequently a laparotomy was performed. A marked induration of the jejunal wall was noticed (Fig. 3) and the above-described gallstone was removed (Fig. 4). Postoperative recovery was uneventful and the patient left the hospital 4 days after surgery.

\section{Discussion}

Gallstone ileus accounts for 1-4\% of all cases of mechanical obstruction in the general population and, in patients over age 65 , it accounts for $25 \%$ of nonstrangulated small bowel obstruction $[1,3]$. The underlying pathophysiology is due to acute or chronic cholecystitis based on cholelithiasis. The inflamed gallbladder becomes adherent to part of the alimentary tract and ischemia and erosion leads to the gallstone eroding through the cholecystic duct or gallbladder wall and intestinal wall to form a biliary-enteric fistula $[2,3]$.

Diagnosis can be made upon a plain radiograph, although less than $15 \%$ of gallstones are visible on a plain abdominal film, since most stones are radiolucent and because gas and bony structures can obscure gallstones outside the biliary tree. Abdominal CT offers better visualization of the impacted stone and can document gallbladder thickening, pneumobilia and intestinal obstruction [4]. Enteroscopy is of relatively limited use for the diagnosis of this condition.

Prompt diagnosis, adequate fluid repletion and relief of intestinal obstruction are essential in the treatment of gallstone ileus. Endoscopic treatment seldom proves to be successful; however, is less invasive compared to surgery and has been described before [5,6]. A very elegant method of endoscopic crushing of gallstones is a combination of electrohydrolic lithotripsy, which is used to "drill" a hole through the stone, and dilation balloons, that are intro- 
duced through the hole and then inflated [7]. Unfortunately, we did not have access to electrohydrolic lithotripsy devices at that time. Mainstay of therapy is surgical enterolithotomy with careful examination of the intestinal tract for additional gallstones. One-stage surgery with combined enterolithotomy, cholecystectomy and fistula-closure remains a matter of debate, since it is associated with a high rate of complications and a high mortality rate [8]. It is primarily recommended in patients who have a low operative risk and in whom findings in the right upper quadrant permit biliary tract inspection and cholecystectomy $[1,2,9,10]$. In high risk patients, it is recommended to perform enterolithotomy alone, followed by elective cholecystectomy at a later date if biliary symptoms persist. However, in the elderly patient, subsequent cholecystectomy is not mandatory $[7,11,12]$.

\section{Conflict of interest}

The authors of the manuscript have no (potential) conflicts of interest to declare. All authors declare that no funding was received for the research described in the manuscript. The integrity of the present case-report is guaranteed by all authors.

\section{References}

1. Reisner RM, Cohen JR. Gallstone ileus: a review of 1001 reported cases. Am Surg 1994;60:441-6.
2. Kirchmayr W, Mühlmann G, Zitt M, Bodner J, Weiss H, Klaus A. Gallstone ileus: rare and still controversial. ANZ J Surg 2005;75:234-8.

3. Vagefi PA, Ferguson CM, Hall JF. Recurrent gallstone ileus: third time is the charm. Arch Surg 2008;143:1118-20.

4. Lassandro F, Romano S, Ragozzino A, Rossi G, Valente T Ferrara I, Romano L, Grassi R. Role of helical CT in diagnosis of gallstone ileus and related conditions. Am J Rontgenol 2005;185:1159-65.

5. Lübbers H, Mahlke R, Lankisch PG. Gallstone ileus: endoscopic removal of a gallstone obstructing the upper jejunum. J Intern Med 1999;246:593-7.

6. Schwacha H, Blum HE, Hafkemeyer P. Endoscopic therapy of gallstone ileus. Endoscopy 2008;40:E185-6.

7. Zielinski MD, Ferreira LE, Baron TH. Successful endoscopic treatment of colonic gallstone ileus using electrohydraulic lithotripsy. World J Gastroenterol 2010;16(12):1533-6.

8. Browning LE, Taylor JD, Clark SK, Karanjia ND. Jejunal perforation in gallstone ileus - a case series. J Med Case Reports 2007;1:157.

9. Ayantunde AA, Agrawal A. Gallstone ileus: diagnosis and management. World J Surg 2007;31:1292-7.

10. Rodriguez-Sanjuan JC, Casado F, Fernández MJ, Morales DJ, Naranjo A. Cholecystectomy and fistula closure versus enterolithotomy alone in gallstone ileus. Br J Surg 1997;84: 634-7.

11. Lobo DN, Jobling JC, Balfour TW. Gallstone ileus: diagnostic pitfalls and therapeutic successes. J Clin Gastroenterol 2000;30:72-6.

12. Muthukumarasamy G, Venkata SP, Shaikh IA, Somani BK, Ravindran R. Gallstone ileus: surgical strategies and clinical outcome. J Dig Dis 2008;9:156-61. 